\title{
Isolasi dan Identifikasi Saponin dari Ekstrak Leunca (Solanium ningrum L) Secara Spektrofotometri Infra Merah
}

\author{
Aden Dhana Rizkita ${ }^{1)}$, Sintia Ayu Dewi' ${ }^{2}$, \\ Emas Agus Prastyo Wibowo ${ }^{2)}$, Ilham Maulana ${ }^{1)}$ \\ 1) Sekolah Tinggi Ilmu Kesehatan Bogor Husada, Bogor, Indonesia \\ 2) Jurusan Kimia Universitas Negeri Semarang, Semarang, Indonesia \\ adendhanarizkita@gmail.com
}

\begin{abstract}
ABSTRAK
Penelitian ini dilakukan untuk mengisolasi dan mengidentifikasi senyawa saponin dengan maserasi menggunakan etanol 95\% sampai mendapat ekstrak kering sebanyak 20 gram dengan dipanaskan menggunakan evaporator. Ekstraksi kedua dilakukan menggunakan corong pisah dengan pelarut dietil eter dan n-butanol. Identifikasi saponin dilakukan dengan tiga parameter uji diantaranya uji busa, uji warna dan gugus fungsi menggunakan Spektrofotometer Infra Merah. Hasil pengukuran Spektrofotometri Infra Merah menunjukkan Ekstrak Daun Launca mengandung beberapa gugus fungsi sebagai berikut : gugus $-\mathrm{OH}$ (puncak yang lebar pada bilangan gelombang $3444,87 \mathrm{~cm}^{-1}$ ), regang $-\mathrm{CH}$ alifatik simetri (bilangan gelombang $2926,01 \mathrm{~cm}^{-1}$ dan $2854,65 \mathrm{~cm}^{-1}$, regang $\mathrm{C}=\mathrm{C}$ tidak terkonjugasi pada bilangan gelombang $1606,7 \mathrm{~cm}^{-1}$, adanya regang $\mathrm{C}-\mathrm{H}$ (bilangan gelombang $1074,35 \mathrm{~cm}^{-1}$ dan $1045,42 \mathrm{~cm}^{-1}$ ), dan adanya vibrasi bengkokan simetris C-O pada bilangan gelombang $1386,82 \mathrm{~cm}^{-1}$.
\end{abstract}

Kata kunci: Daun leunca; spektrofotometer infra merah; saponin

\section{Isolation and Identification of Saponin from Leunca (Solanium ningrum L) Extract by Infrared Spectrophotometry}

\begin{abstract}
This research was conducted to isolate and identify saponin compounds by maceration using $95 \%$ ethanol to obtain 20 grams of dry extract by heating using an evaporator. The second extraction was carried out using a separating funnel with diethyl ether and n-butanol as solvents. Saponin identification was carried out with three test parameters including foam test, color test and functional group using Infrared Spectrophotometer. Infrared Spectrophotometry measurement results show that the Launca Leaf Extract contains the following functional groups: -OH group (wide peak at wave number $3444.87 \mathrm{~cm}-1$ ), aliphatic symmetrical $-\mathrm{CH}$ stretch (wave number $2926.01 \mathrm{~cm}-1$ and $2854,65 \mathrm{~cm}-1$, unconjugated $\mathrm{C}=\mathrm{C}$ stretch at wave number $1606.7 \mathrm{~cm}-1$, presence of $\mathrm{CH}$ stretch (wave number $1074.35 \mathrm{~cm}-1$ and $1045.42 \mathrm{~cm}-1$ ), and the presence of symmetrical bending vibration of $\mathrm{CO}$ at wave number $1386.82 \mathrm{~cm}-1$.
\end{abstract}

Keywords: Infra red spectrophotometer; leunca leaf; saponin

(Article History: Received 06-07-2021; Accepted 20-10-2021; Published 29-10-2021)

\section{PENDAHULUAN}

Kebanyakan Tumbuhan di Indonesia pada umumnya mengandung senyawa aktif dalam bentuk metabolit sekunder seperti terpenoid, steroid, kumarin, flavonoid dan alkaloid (Sari et al., 2015). Senyawa metabolit sekunder tersebut telah banyak digunakan sebagai zat warna, racun, aroma makanan maupun sebagai obat-obatan (Lenny, 2006; Putriantari et al., 2014). Alkaloid, flavonoid, senyawa fenol, steroid, dan terpenoid dikenal sebagai metabolit sekunder yang bersifat antioksidatif (Marliana, 2007; Santosa et al.,
2017). Kegunaan tumbuhan tidak terlepas dari kandungan senyawa kimianya, satu tumbuhan obat terdapat lebih dari satu senyawa kimia (Herlina, 2011). Tergantung dari iklim, ketinggian, jenis tanah, perlakuan terhadap tanaman (Yuniarti, 2008). Salah satu tanaman yang mempunyai khasiat sebagai obat tradisional adalah daun leunca (Solanum nigrum L) yang secara empirik digunakan sebagai obat tipoid, menurunkan panas tubuh, dan tekanan darah tinggi (Arisandi, 2008). Daun leunca memiliki kandungan kimia seperti saponin, polifenol, sodium, calcium, 
miasin, fosfor, folat, dan magnesium (Joseph, 2002; Sabu \& Kalpana, 2017).

Penelitian tentang daun leunca sebelumnya telah dilakukan oleh Putriantari et al. (2014), tentang uji antiproliferatif fraksi kloroform dari ekstrak etanol daun leunca terhadap sel hela serta Raditya Prima Istiaji, tentang uji fitokimia estrak daun leunca yang berpotensi sebagai imunostimulan sehingga muncul pemikiran baru ketika diidentifikasi menggunakan instrument penunjang identifikasi seperti spektrofotometer infra merah, akan lebih memastikan kebenaran kandungan saponin pada daun leunca tersebut.

Berdasarkan uraian tersebut diatas maka permasalahan yang timbul dalam penelitian adalah apakah pada ekstrak daun leunca terdapat kandungan saponin secara spektrofotometri infra merah.

Adapun tujuan dari penelitian ini yaitu untuk mengidentifikasi senyawa (komponen) saponin pada ekstrak Daun Leunca secara spektrofotometri Infra merah. Manfaat penelitian ini yaitu memberikan informasi tentang data kimia berupa komponen kimia saponin serta manfaat yang terdapat dalam daun Leunca dapat menjadi acuan untuk peneliti selanjutnya.

\section{METODE PENELITIAN}

Penelitian ini dilakukan di Laboratorium Kimia Prodi Farmasi, STIkes Bogor Husada, pada bulan Januari 2020. Jenis penelitian yang dilakukan adalah penelitian eksperimental yang merupakan penelitian laboratorium yang menggunakan alat Spektrovotometri Infra merah. Dengan desain penelitian yaitu identifikasi senyawa saponin dari ekstrak Leunca (Solanium ningrum L) secara spektrofotometri Infra merah.

Bahan yang digunakan dalam penelitian ini adalah aquades, alumunium foil, alumunium klorida, asam sulfat $10 \%$, ekstrak daun leunca, etanol, $\mathrm{FeCl}_{3}$, pereaksi Liebermann Burchard (LB), n-butanol, kloroform, metanol, Spektrofotometri infra merah (Lestari et al., 2016).

Metode Penelitian yang ditempuh yaitu:

1) Pengambilan sampel, yaitu daun leunca disortir, dibersihkan, dipotong kecil-kecil, dan dikeringkan menggunakan sinar matahari.

2) Bahan diekstraksi meggunakan 3 jenis pelarut yaitu etanol $95 \%$, dietil eter, nbutanol (Santosa et al., 2015). Pertama daun yang telah disortir di maserasi menggunakan etanol $95 \%$ sampai memperoleh ekstrak kering menggunakan evaporator, kemudian ekstrak methanol tersebut disuspensi dengan air suling, kemudian diekstraksi dengan dietil eter 50 $\mathrm{ml}$ dalam corong pisah, dilakukan sebanyak 3 kali, ekstrak dietil eter ditampung lalu diuapkan (Pratiwi, et al. (2011). Lapisan air kemudian diekstraksi dengan n-butanol setelah itu diuapkan sampai diperoleh ekstrak kental. Lapisan air yang diperoleh disuspensi dengan air suling, kemudian diekstraksi dengan nbutanol $50 \mathrm{ml}$ dalam corong pisah dilakukan sebanyak 3 kali, dan diperoleh dua lapisan yaitu lapisan air dan lapisan nbutanol. Lapisan n-butanol diuapkan dan diperoleh ekstrak n-butanol kental kemudiabn dicuci dengan dietil eter dan dilarutkan dengan metanol lalu disaring kemudian diperoleh dua lapisan yaitu dietil eter dan lapisan metanol, lalu pada lapisan ini ditambahkan dengan dietil eter berlebih lalu disaring kembali dan endapan yang diperoleh menandakan adanya endapan saponin, kemudian untuk lebih jelas dilakukan uji pendahuluan untuk mengetahui ada atau tidaknya endapan saponin.

3) Uji pendahuluan saponin berupa uji busa dan uji warna.

4) Identifikasi menggunakan spektrofotometer infra merah.

\section{HASIL DAN PEMBAHASAN}

Hasil disajikan secara logis, singkat, dan sistematis (tabel dan ilustrasi penting harus disertakan). Pembahasan merupakan tinjauan atas hasil penelitian; terkait di dalamnya, argumentasi logis serta perbandingan dengan hasil-hasil penelitian lain (rujukan literatur).

Penelitian yang telah dilakukan didapatkan hasil, pada proses ekstraksi terhadap 500 gram sampel Daun Leunca (Solanium ningrum L) dengan memakai pelarut etanol $95 \%$ diperoleh ekstrak etanol kental, kemudian dipartisi cair-cair dengan menggunakan pelarut yang sesuai sampai diperoleh ekstrak eter. Dari ekstrak yang diperoleh dilakukan uji pendahuluan yaitu dengan menggunakan uji busa dan pereaksi warna kemudian dilanjutkan dengan spektrofotometri infra merah. Hasil uji 
pendahuluan saponin dengan menggunakan uji busa dapat dilihat pada Tabel 1 dimana pada tabel ini membuktikan adanya senyawa Saponin dengan menggunakan metode uji Busa dengan pereaksi $\mathrm{HCl}$. Hasil uji pendahuluan saponin dengan menggunakan uji pereaksi warna dapat dilihat pada Tabel 2 . hasil ini memperkuat uji pendahuluan dengan indikator warna. Tabel 3 menggambarkan hasil analisis spektrum infra merah yang menandakan bahwa sampel mengandung Saponin dengan melihat gugus Hodroksi, Karboksil, dan C=C aromatis (Hedges, 2007).

Tabel 1. Hasil Uji Pendahuluan Saponin dengan menggunakan Uji Busa

\begin{tabular}{ccccc}
\hline No & Sampel & Pereaksi & Hasil & Ket \\
\hline \multirow{4}{*}{1} & Simplisia & & Busa stabil & \\
& Daun & $\mathrm{HCl} 2 \mathrm{~N}$ & $1-3 \mathrm{~cm}$ & $(+)$ \\
& Leunca & & & \\
\hline
\end{tabular}

Tabel 2. Hasil Uji Pendahuluan Saponin dengan menggunakan Uji Pereaksi Warna

\begin{tabular}{ccccc}
\hline No & Sampel & Pereaksi & Hasil & Ket \\
\hline \multirow{3}{*}{1} & Simplisia & Kloroform & Cincin & \\
& Daun & + pereaksi & Coklat & $(+)$ \\
& Leunca & LB & C & \\
\hline
\end{tabular}

Tabel 3. Hasil Analisis Spektrum Infra Merah

\begin{tabular}{|c|c|c|c|c|}
\hline \multirow{2}{*}{$\begin{array}{l}\text { Pun } \\
\text { cak }\end{array}$} & \multicolumn{2}{|c|}{$\begin{array}{l}\text { Bilangan gelombang } \\
\left(\mathrm{cm}^{-1}\right)\end{array}$} & \multirow{2}{*}{$\begin{array}{c}\text { Jenis } \\
\text { Vibrasi }\end{array}$} & \multirow{2}{*}{$\begin{array}{c}\text { Inte } \\
\text { nsit } \\
\text { as }\end{array}$} \\
\hline & Isolat 1 & Pustaka & & \\
\hline 1 & 3444,87 & $3500-3300$ & $\begin{array}{l}\mathrm{O}-\mathrm{H} \\
\text { stretch }\end{array}$ & Vs \\
\hline 2 & & $2900-2700$ & $\begin{array}{c}\text { C-H } \\
\text { (Alkana) } \\
\text { stretch }\end{array}$ & $\mathrm{m}-\mathrm{s}$ \\
\hline 3 & 1606,7 & $1650-1450$ & $\begin{array}{c}\mathrm{C}=\mathrm{C} \\
\text { stretch } \\
\mathrm{C}-\mathrm{O}\end{array}$ & $\mathrm{m}$ \\
\hline 4 & 1386,82 & $1340-1470$ & $\begin{array}{l}\text { (Alkana) } \\
\text { bending } \\
\text { of methyl }\end{array}$ & M \\
\hline 5 & $\begin{array}{l}1074,35 \\
1045,35\end{array}$ & $1300-1000$ & $\begin{array}{c}\text { C-H } \\
\text { stretch of } \\
\text { carbonyl }\end{array}$ & $\mathrm{m}-\mathrm{s}$ \\
\hline
\end{tabular}

Keterangan: vs (very strong), s (strong), m (medium), $\mathrm{w}($ weak $)$

Simplisia daun leunca sebanyak 500 gram diekstraksi dengan maserasi dalam dengan etanol 95\%. Etanol 95\% dapat mengikat semua ekstrak yang terkandung dalam sampel yang telah dihasilkan, baik bersifat polar maupun non polar.dari hasil maserasi dan penguapan dengan rotapavor diperoleh ekstrak kering sebanyak 20 gram.

Tahap selanjutnya ekstrak daun Leunca ini dipartisi (dipisahkan) senyawa nonpolar, dan senyawa polar dengan menggunakan metode partisi cair-cair pemisahan dilakukan berdasarkan tingkat kepolarannya. Pelarut partisi pertama yang digunakan adalah pelarut eter karena eter merupakan pelarut nonpolar. Pelarut partisi kedua yang digunakan adalah nbutanol karena n-butanol merupakan pelarut polar yang mampu menarik senyawa polar, dan senyawa yang akan ditarik yaitu saponin yang merupakan senyawa polar.

Untuk identifikasi pertama-tama dilakukan uji pendahuluan dengan menggunakan uji busa. Uji busa meliputi dengan simplisia sebanyak 0,5 gram dimasukkan ke dalam tabung reaksi yang telah berisikan aquades $10 \mathrm{ml}$, dikocok dan ditambahkan 1 tetes larutan asam klorida $2 \mathrm{~N}$. Diperhatikan ada atau tidak adanya busa stabil. Sampel mengandung saponin jika terbentuk busa stabil dengan ketinggian 1-3 $\mathrm{cm}$ selama 30 detik dan hasil yang di dapatkan positif mengandung saponin. Setelah itu dilanjutkan dengan uji pendahuluan dengan menggunakan uji warna.

Uji warna meliputi simplisia sebanyak 0,5 gram dimasukkan ke dalam tabung reaksi yang telah berisikan kloroform $10 \mathrm{ml}$, dipanaskan selama 5 menit dengan penangas air sambil dikocok kemudian ditambahkan beberapa tetes pereaksi LB. Jika terbentuk cicin coklat atau violet maka menunjukkan adanya saponin triterpen, sedangkan warna hijau atau biru menunjukkan adanya saponin. Dan hasil yang di dapatkan positif mengandung saponin.

Hasil pengukuran spektrofotometri infra merah menunjukkan ekstrak daun leunca mengandung beberapa gugus fungsi sebagai berikut : gugus $-\mathrm{OH}$ (puncak yang lebar pada bilangan gelombang $3444,87 \mathrm{~cm}^{-1}$ ), regang $\mathrm{CH}$ alifatik simetri (bilangan gelombang $2926,01 \mathrm{~cm}^{-1}$ dan $2854,65 \mathrm{~cm}^{-1}$, regang $\mathrm{C}=\mathrm{C}$ tidak terkonjugasi pada bilangan gelombang $1606,7 \mathrm{~cm}^{-1}$, adanya regang $\mathrm{C}-\mathrm{H}$ (bilangan gelombang $1074,35 \mathrm{~cm}^{-1}$ dan $1045,42 \mathrm{~cm}^{-1}$ ), dan adanya vibrasi bengkokan simetris $\mathrm{C}-\mathrm{O}$ pada bilangan gelombang $1386,82 \mathrm{~cm}^{-1}$. Hasil spektrum pengukuran gugus fungsi ekstrak daun leunca menggunakan spektrofotometri infra merah dapat dilihat pada Gambar 1 yang membuktikan bahwa hasil spektrum gugus 
fungsi daun leunca mengandung gugus gugus karbonil, hidroksi, cincin $\mathrm{C}=\mathrm{C}$ aromatis, dan hidrokarbon.

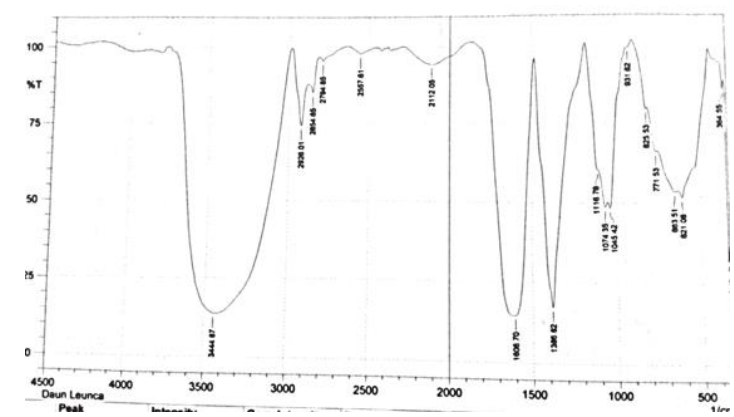

Gambar 1. Hasil spektrum gugus fungsi ekstrak daun leunca menggunakan spektrofotometri infra merah

\section{KESIMPULAN}

Berdasarkan hasil penelitian yang telah dilakukan daun leunca (Solanium ningrum L) secara spektrofotometri infra merah maka dapat disimpulkan bahwa daun leunca (Solanium ningrum L) tersebut teridentifikasi adanya senyawa saponin dengan hasil spektum infra merah yang ditandai dengan adanya gugus $-\mathrm{OH}$, gugus karbonil $\mathrm{C}-\mathrm{O}$, cincin $\mathrm{C}=\mathrm{C}$ aromatis, dan rentangan dua gugus $\mathrm{C}-\mathrm{H}$ pada kedua senyawa kimia tersebut.

\section{DAFTAR PUSTAKA}

Arisandi, Y. 2008. Manfaat dan Kegunaan Tanaman Leunca. Dinas Kesehatan Provinsi Bali, Denpasar.

Hedges. 2007. Relationship Between Cemical Structure and Biologica Activities of Triterpenoid Saponin from Soybean (Review). Biosience Biotechnology and Biochemistry, 62: 2291-2292.

Herlina, W. 2011. Tetumbuhan Sebagai Sumber Bahan Obat. Pusat Penelitian Universitas Andalas, Padang.

Joseph, G. 2002. Manfaat Tanaman Leunca Bagi Kesehatan Kita, Available (Online). http://giosephid@yahoo.com. Diaskes 12 Maret 2014.

Lenny, S. 2006. Senyawa flavonoida, fenilpropanoida dan alkaloida. Departemen Kimia Fakultas Matematika dan Ilmu Pengetahuan Alam Universitas Sumatera Utara, Medan.
Lestari, Y., Ardiningsih, P. \& Nurlina. 2016. Aktivitas antibakteri gram positif dan gram negatif dari ekstrak dan fraksi daun nipah (Nypa fruticans wurmb.) asal pesisirsungai kakap Kalimantan Barat. Jurnal Kimia Khatulistiwa, 5(4): 1-8.

Marliana. 2007. Tumbuhan Obat Nusantara. Cetakan I. PT Cahaya Abadi, Jakarta.

Pratiwi, R.S., Tjiptasurasa \& Wahyuningrum, R. 2011. Aktivitas Antibakteri Ekstrak Etanol Kayu Nangka (Artocarpus heterophylla Lmk.) Terhadap Bacillus subtilis dan E. coli. Pharmacy, 8(3):110.

Putriantari, M. \& Sentosa, E. 2014. Pertumbuhan dan kadar alkaloid tanaman leunca (Solanum americanum Miller) pada beberapa dosis nitrogen. Jurnal Hortikultura Indonesia, 5(3): 175-182.

Sabu, R., \& Kalpana, C,A. 2017. Cultivation of Solanum nigrum under controlled environment using organic fertilizer. International Journal of Applied Home Science, 4(7): 519-524.

Santosa, E., Prawati, U., Sobir, Mine, Y. \& Sugiyama, N. 2015. Agronomy, utilization and economics of indigenous vegetables in West Java, Indonesia. Jurnal Hortikultura Indonesia, 6(3): 125-134. https://doi.org/10.29244/ jhi.6.3.125-134.

Santosa, E., Putriantari, M., Nakano, H., Mine, Y. \& Sugiyama, N. 2017. Canopy achitecture, biomass and fruit production of Solanum nigrum L. as determined by nitrogen application. Jurnal Hortikultura Indonesia, 8(3): 162-170. https://doi.org/10.29244/ jhi.8.3. 162-170.

Sari, I.D., Yuniar, Y., Siahaan, S., Riswati \& Syaripuddin, M. 2015. Tradisi Masyarakat dalam Penanaman dan Pemanfaatan Tumbuhan Obat Lekat di Pekarangan. Jurnal Kefarmasian Indonesia, 5(2):123-132.

Yuniarti. 2008. Kitab Tumbuhan Obat Nusantara. Cetakan I. PT Buku Seru. Jakarta. 